\title{
Income inequality and subjective well-being: a systematic review and meta-analysis
}

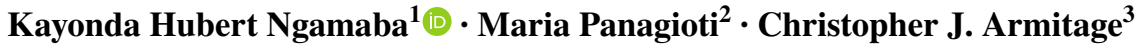

Accepted: 12 October 2017 / Published online: 24 October 2017

(C) The Author(s) 2017. This article is an open access publication

\begin{abstract}
Background Reducing income inequality is one possible approach to boost subjective well-being (SWB). Nevertheless, previous studies have reported positive, null and negative associations between income inequality and SWB.

Objectives This study reports the first systematic review and meta-analysis of the relationship between income inequality and SWB, and seeks to understand the heterogeneity in the literature.

Methods This systematic review was conducted according to guidance (PRISMA and Cochrane Handbook) and searches (between January 1980 and October 2017) were carried out using Web of Science, Medline, Embase and PsycINFO databases.

Results Thirty-nine studies were included in the review, but poor data reporting meant that only 24 studies were included in the meta-analysis. The narrative analysis of 39 studies found negative, positive and null associations
\end{abstract}

Electronic supplementary material The online version of this article (doi:10.1007/s11136-017-1719-x) contains supplementary material, which is available to authorized users.

Christopher J. Armitage

Chris.armitage@manchester.ac.uk

1 Department of Social Policy and Social Work, International Centre for Mental Health Social Research, University of York, York, UK

2 NIHR School for Primary Care Research, Manchester Academic Health Science Centre, University of Manchester, Manchester, UK

3 Division of Psychology and Mental Health, Manchester Centre for Health Psychology, School of Health Sciences, Manchester Academic Health Science Centre and NIHR Manchester Biomedical Research Centre, University of Manchester, Oxford Road, Manchester M13 9PL, UK between income inequality and SWB. The meta-analysis confirmed these findings. The overall association between income inequality and SWB was almost zero and not statistically significant (pooled $r=-0.01,95 \% \mathrm{CI}-0.08$ to 0.06 ; $\left.Q=563.10, I^{2}=95.74 \%, p<0.001\right)$, suggesting no association between income inequality and SWB. Subgroup analyses showed that the association between income inequality and SWB was moderated by the country economic development (i.e. developed countries: $r=-0.06,95 \% \mathrm{CI}-0.10$ to -0.02 versus developing countries: $r=0.16,95 \% \mathrm{CI}$ $0.09-0.23)$. The association between income inequality and SWB was not influenced by: (a) the measure used to assess SWB, (b) geographic region, or (c) the way in which income inequality was operationalised.

Conclusions The association between income inequality and SWB is weak, complex and moderated by the country economic development.

Keywords Subjective well-being $\cdot$ Happiness $\cdot$ Life satisfaction $\cdot$ Income inequality $\cdot$ Redistribution

\section{Introduction}

Income inequality is one of many possible determinants of subjective well-being (SWB) [1,2]. There is a view that income inequality - the unequal distribution of household income across different participants in an economy (OECD, 2011) - is a predictor of SWB and that decreasing income inequality will boost SWB [3, 4]. However, the assumed linear relationship between income inequality and SWB is not grounded in a solid research evidence base. In fact, our scoping search yielded studies that showed mixed findings: some studies show a significant positive association between SWB and income inequality $[5,6]$, some show a significant 
negative association $[4,7,8]$ and others show no significant association [9]. One explanation of these inconsistent findings is that the strength and the direction of the relationship between SWB and income inequality are moderated by other factors. For example, although both happiness and life satisfaction have been used interchangeably to assess SWB across different studies, these terms are not synonymous and might relate differently to income inequality [10]. Similarly, the literature suggests that level of economic development $[11,12]$, geography [8] and how income inequality is operationalised [13] may affect the relationship between income inequality and SWB [14].

Given that the relationship between income inequality and SWB is important to social policy decisions, it is surprising that no systematic evaluation of this literature has yet been undertaken. We therefore decided to undertake the first systematic review of the literature to examine the link between income inequality and SWB. The objectives were:

1. to examine the direction and the magnitude of the association between income inequality and SWB;

2. to examine the factors that may moderate the association between income inequality and SWB. On the basis of previous research evidence, we focused on the effects of

- types of measures of SWB (i.e. happiness versus life satisfaction),

- country level of development (i.e. developed countries versus developing countries),

- geographic region (e.g. studies conducted in the USA versus studies conducted in Europe).

- the way income inequality was operationalised (exogenous Gini versus endogenous Gini).

\section{Methods}

The systematic review was conducted and reported according to PRISMA (Preferred Reporting Items for Systematic Reviews and Meta-Analyses) and Cochrane Handbook recommendations $[15,16]$.

\section{Search strategy and data sources}

Systematic searches of the literature published between January 1980 and October 2017 were carried out using Web of Science, Medline, Embase and PsycINFO. Combinations of two key blocks of terms were used: (1) SWB, happiness, life satisfaction, quality of life, well-being and (2) income inequality, income level, social equality, income disparities, income redistribution. We also checked the reference lists of the studies meeting our inclusion criteria. The search strategy in each of the databases is presented in Appendix 1 (see Supplementary Material).

\section{Study selection}

Screening was completed in two stages. Initially, the titles and abstracts of the identified studies were screened for eligibility. Next, the full texts of studies initially assessed as "relevant" for the review were retrieved and checked against our inclusion/exclusion criteria. Authors were contacted and asked for further information if necessary, most frequently for the zero-order correlation between income inequality and SWB [17]. The screening process is presented in Appendix 2 (see Supplementary Material).

\section{Eligibility criteria}

Studies were eligible for inclusion if they met the following criteria:

1. Original studies that employed quantitative methods. Qualitative studies were excluded.

2. Included a measure of income inequality (i.e. exogenous Gini and endogenous Gini).

3. Included a measure of SWB (happiness and/or life satisfaction) $[18,19]$.

4. Provided quantitative data regarding the association between income inequality and SWB.

5. Were published in a peer-reviewed journal. Grey literature was excluded because they were not published through conventional and credible publishers.

\section{Data extraction}

Information about the following characteristics of the studies was extracted: (1) first author name and year of publication, country where study was conducted, participant characteristics, period of the study, data used, research design, measures of SWB, measure of income inequality, zero-order correlations, regression coefficient, direction of the association, country level of development; and (2) methodological quality of the study, namely validity of measures, quality of the research design, population and recruitment methods, and control of confounders. Data extraction was completed by the first author. A second researcher extracted data from three randomly selected studies.

\section{Assessment of methodological quality}

The quality review included assessment of the quality of the research design, population and recruitment methods, verified if the choice of the income inequality measure and SWB measures were valid and reliable, and if the analysis 
reported the association between income inequality and SWB (Table 1). Of 39 studies, 15 were given a high-quality rating of $6 / 6$ and the remaining 24 studies were given a lower quality rating of $5 / 6$.

\section{Narrative synthesis}

The narrative synthesis of all 39 eligible studies focused on the way SWB is assessed, country level of development, geographic region and the way income inequality was operationalised.

\section{Data analysis}

Our plan was to pool the results of the association between income inequality and SWB across the individual studies using meta-analysis. Authors of published papers that did not report data in a form amenable for meta-analysis were contacted and eight authors provided further information. We performed a meta-analysis on all 24 studies reporting the correlation coefficients between income inequality and SWB. Studies that assessed both happiness and life satisfaction were reported separately in the subgroups in order to test whether variation is due to the way SWB was assessed. Using the World Bank classification of countries, we performed another subgroup analysis to examine whether the results differed between developed and developing countries. According to the World Bank, developed countries are defined as industrial countries, advanced economies with high level of Gross National Income (GNI) per capita of 12,736 US dollars per year (estimated in July 2015) [20, 21]. In contrast, developing countries includes countries with low and middle levels of GNI per capita ( $>12,736$ US dollars) $[20,21]$.

The associated Confidence Intervals (CI) of the zeroorder correlations were calculated in STATA 13.1 [22]. The pooled zero-order correlation as well as the forest plots were computed using the meta-an command for STATA [22]. A random effects model was used for all the metaanalyses because of anticipated heterogeneity. Heterogeneity was assessed using the Cochran's Q and Higgin's $I^{2}$ statistic [16]. We focus our interpretation of the results in terms of effect sizes [23]. To test whether the association between income inequality and SWB varies across subgroups, we used Cohen's q to test whether there were significant differences in the magnitudes of the correlation coefficients following Fisher's z transformation of $r$ [24]. By convention, if $z$ score values are greater than or equal to 1.96 or less than or equal to -1.96 , the two correlation coefficients are significantly different at a 0.05 alpha level (suggesting difference of correlation coefficients between two population groups) $[25,26]$.

\section{Results}

A total of 619 titles were retrieved, and after removing duplicates $(n=250), 336$ journal articles, 30 books and 5 dissertations were screened for relevance. Following tittle/abstract and full-text screening, 39 articles were deemed eligible for the narrative analysis and 24 studies were eligible for meta-analysis. The flowchart of the screening and selection process is shown in Fig. 1.

\section{Descriptive characteristics of the studies}

Table 1 presents the main characteristics of the 39 articles included in the review. Table 1 provides details about the country in which each study was conducted, participant characteristics, data used, research design and measures used to assess SWB and income inequality. Table 1 presents the zero-order correlation and regression coefficients, the outcome of the association between income inequality and SWB, and the quality ratings.

Six studies were conducted in the USA, 11 studies were conducted in Europe, two in Latin America, ten worldwide (including all continents) and nine elsewhere or used different groupings (e.g. three in China, two in Industrialised countries, one in Russia, one in Israel, one in developing countries and one in Taiwan)_-please see Table 1 for more details. All studies were published between 1977 and 2015 and participants were adults aged between 16 and 99 years. The sample size varied from 1277 to 278,134 and recruited from different groups including students, workers, selfemployed and general population. Studies used data from a range of surveys such as the General Social Survey (GSS), World Value Survey (WVS), Eurobarometer, world database of happiness (WDH), European quality of life (EQL) and Chinese Household Income Project (CHIP). Most studies were conducted in developed nations. Only four studies were conducted exclusively in developing countries (three studies in China and one study in Russia). Different measures were used to assess SWB (e.g. happiness [4] and life satisfaction [12]) and income inequality (e.g. Gini coefficient [28], 80/20 skew [29]).

\section{Narrative synthesis of the results including studies with non-amenable data}

Thirty-nine studies were included for the narrative analysis of the association between income inequality and SWB. The overall evidence for the relationship between income inequality and SWB was mixed, negative, positive or nonsignificant across studies (see Table 1). The narrative synthesis focused on four factors. 


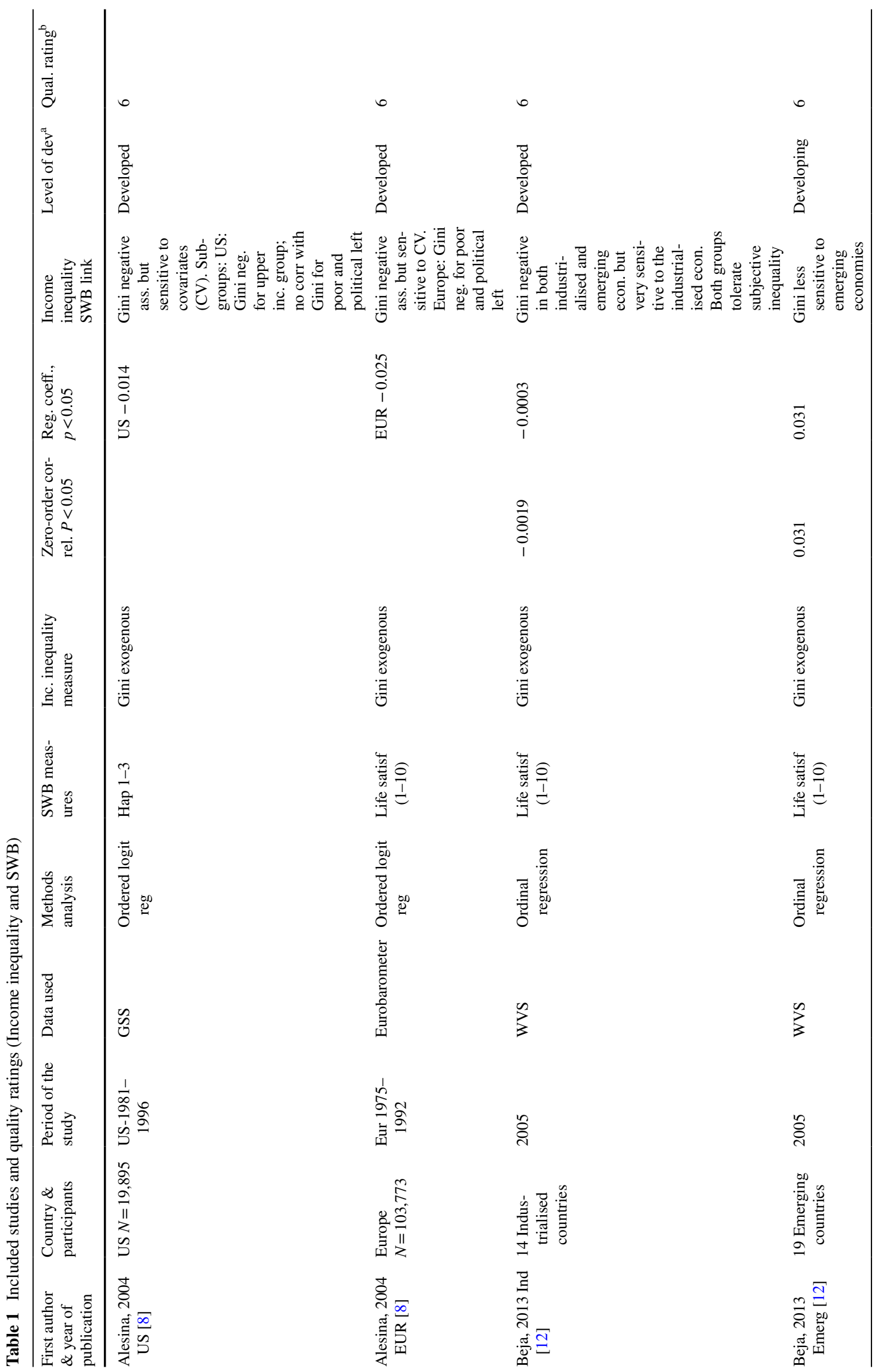




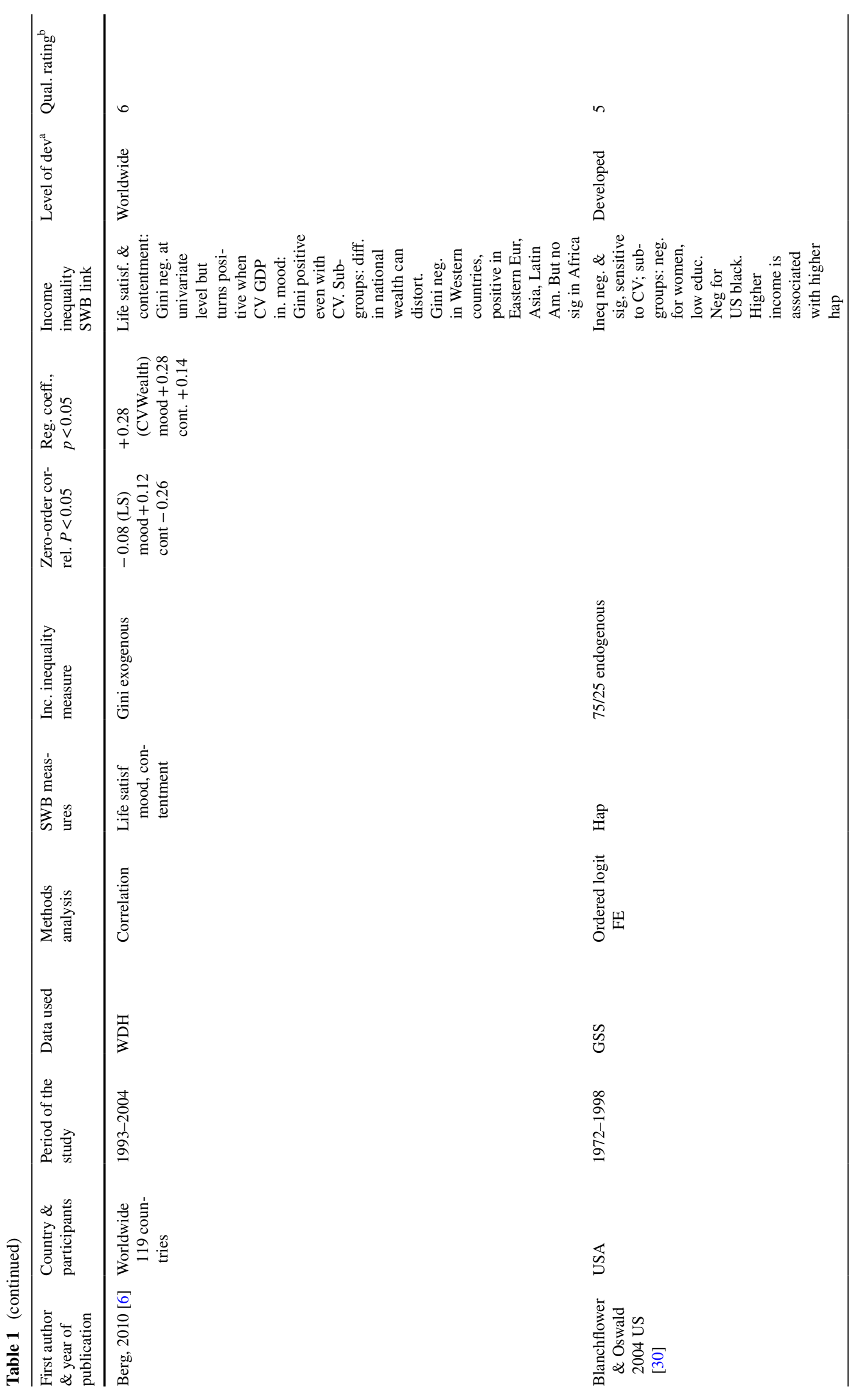




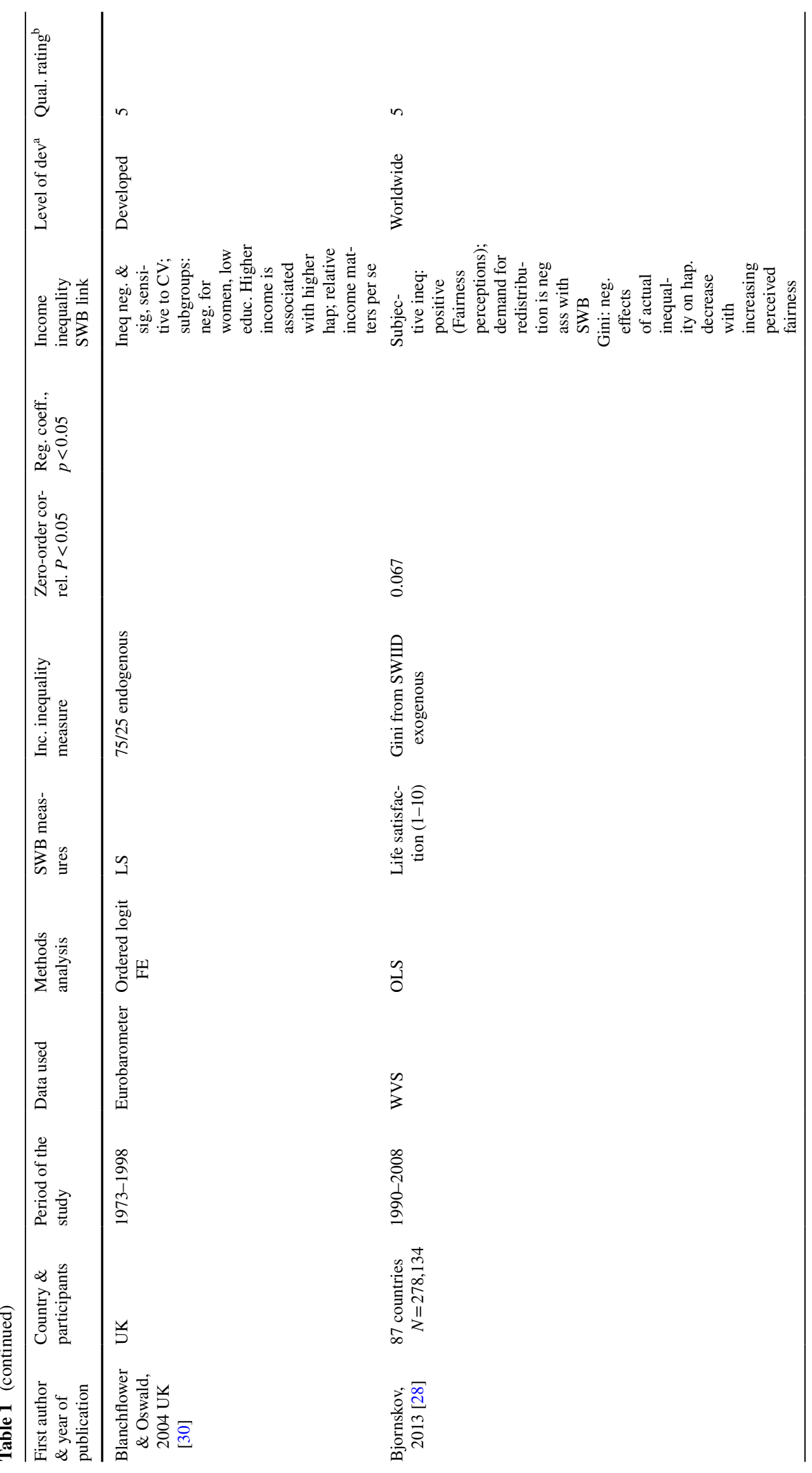




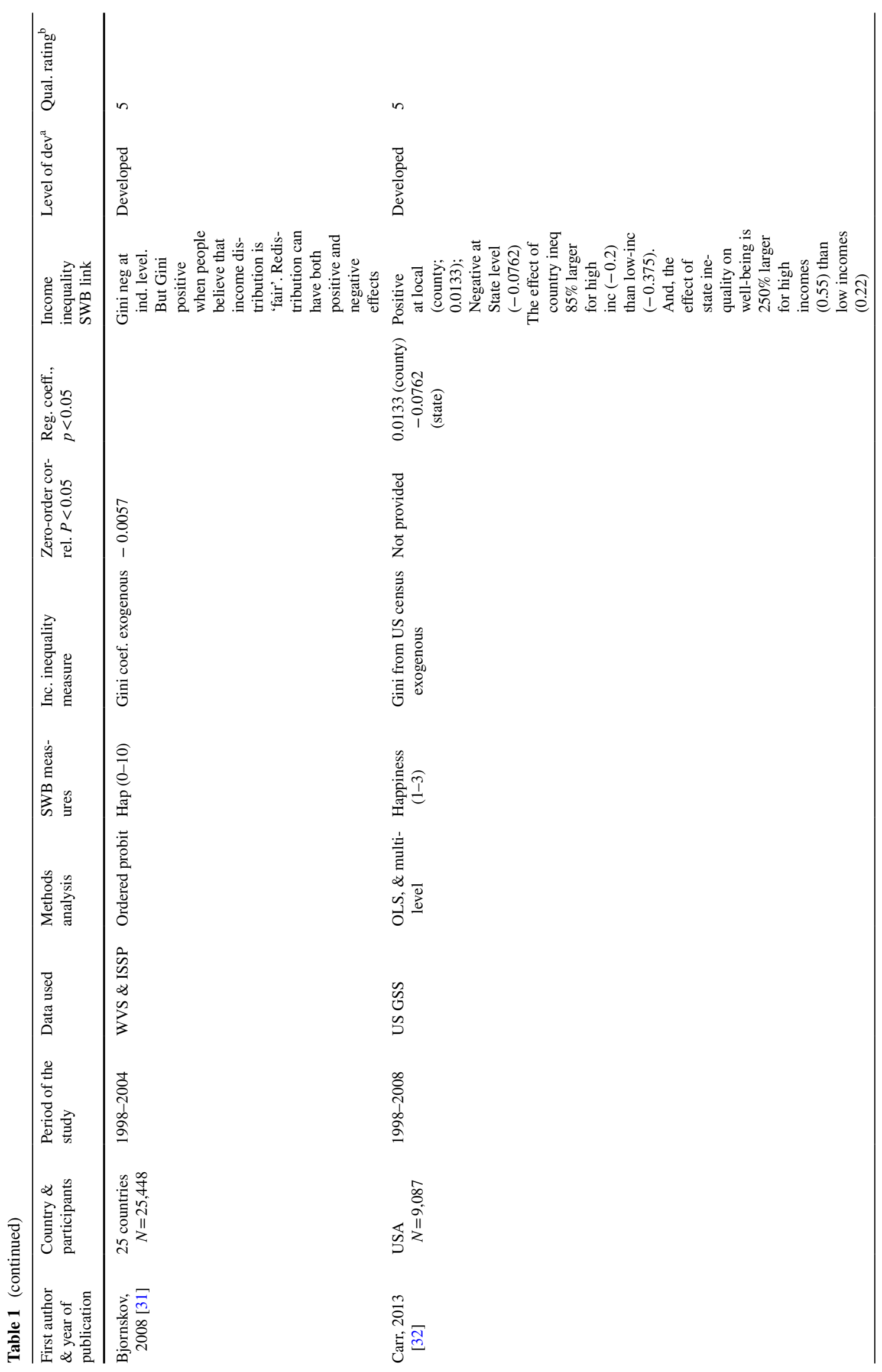




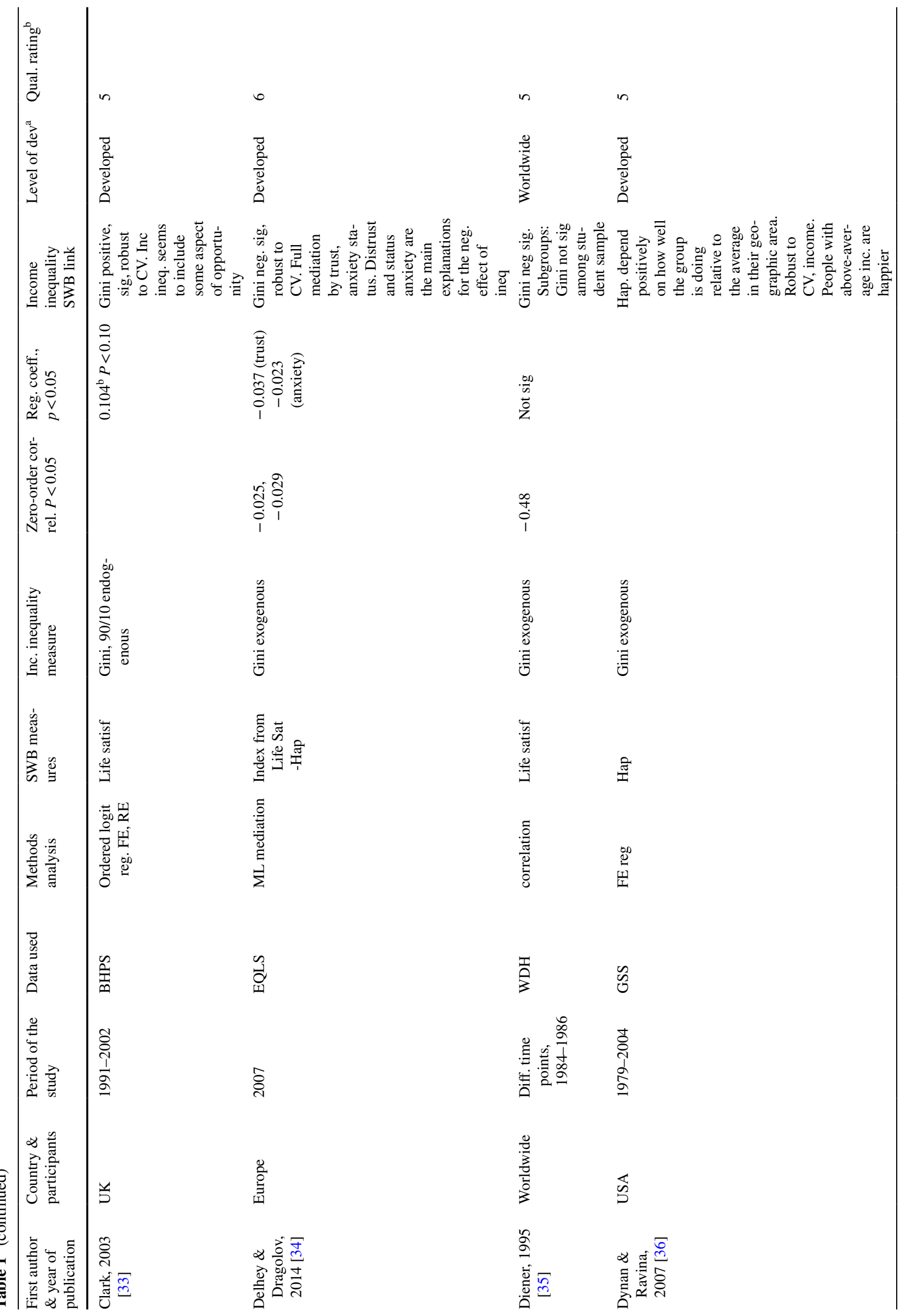




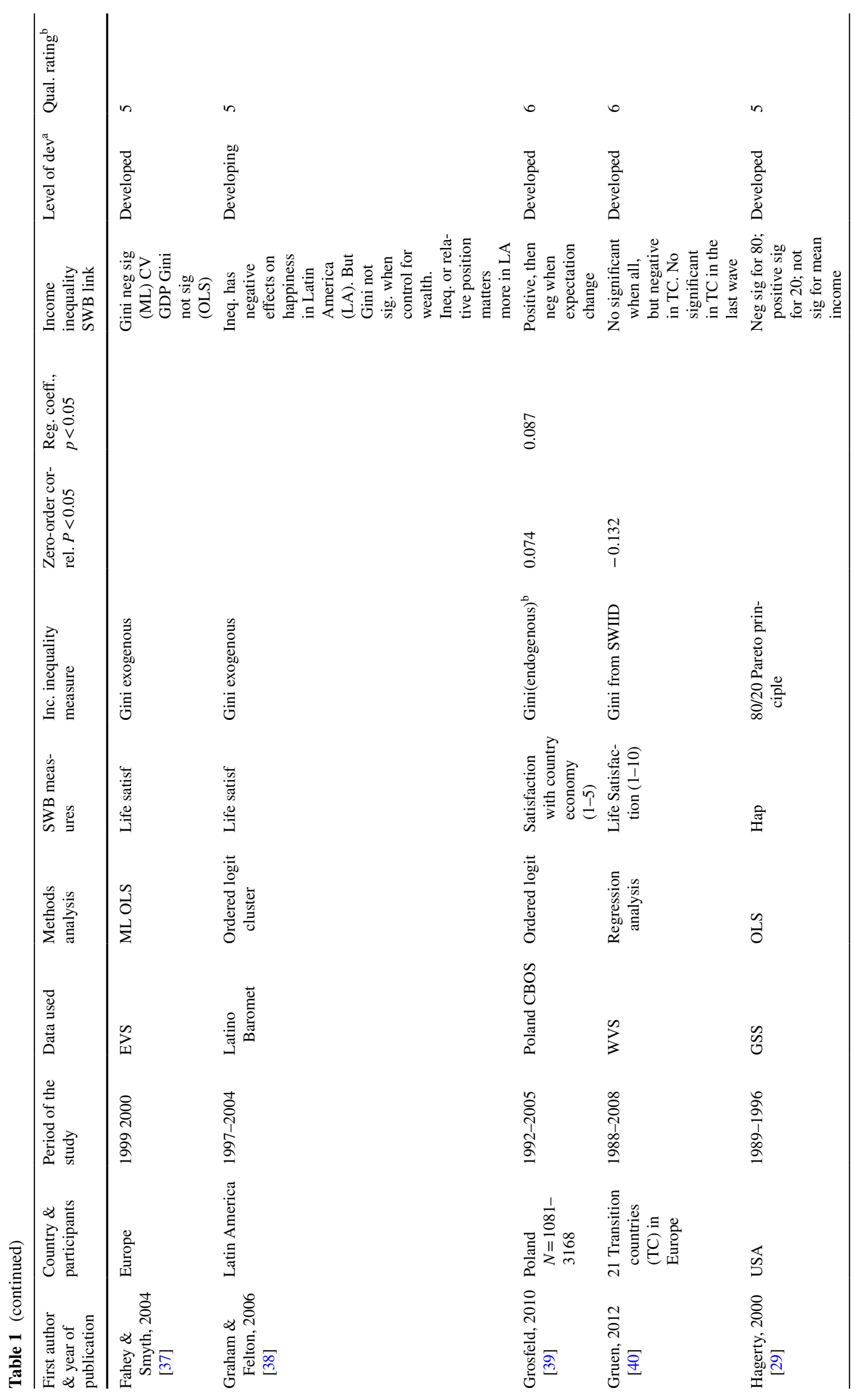




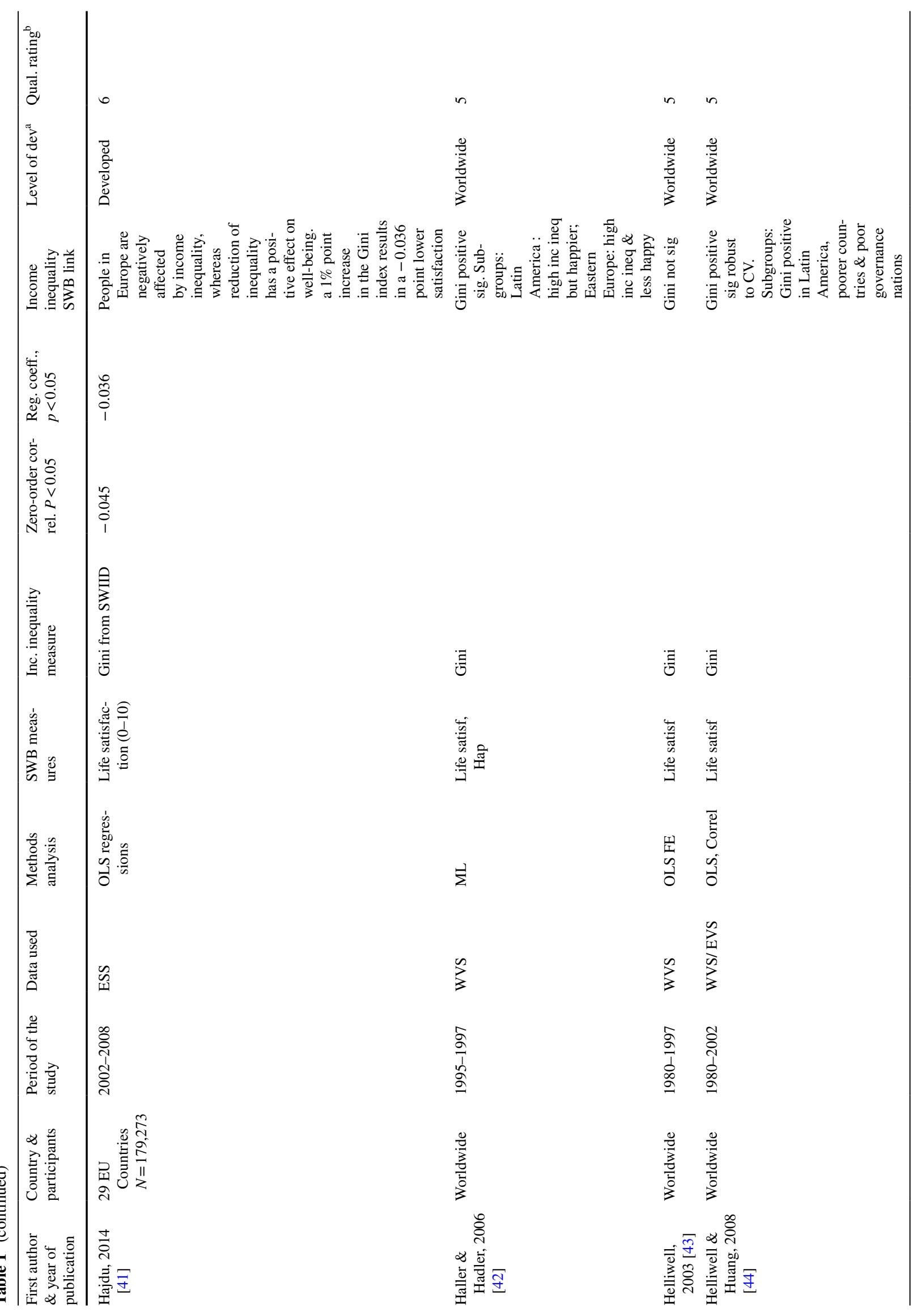




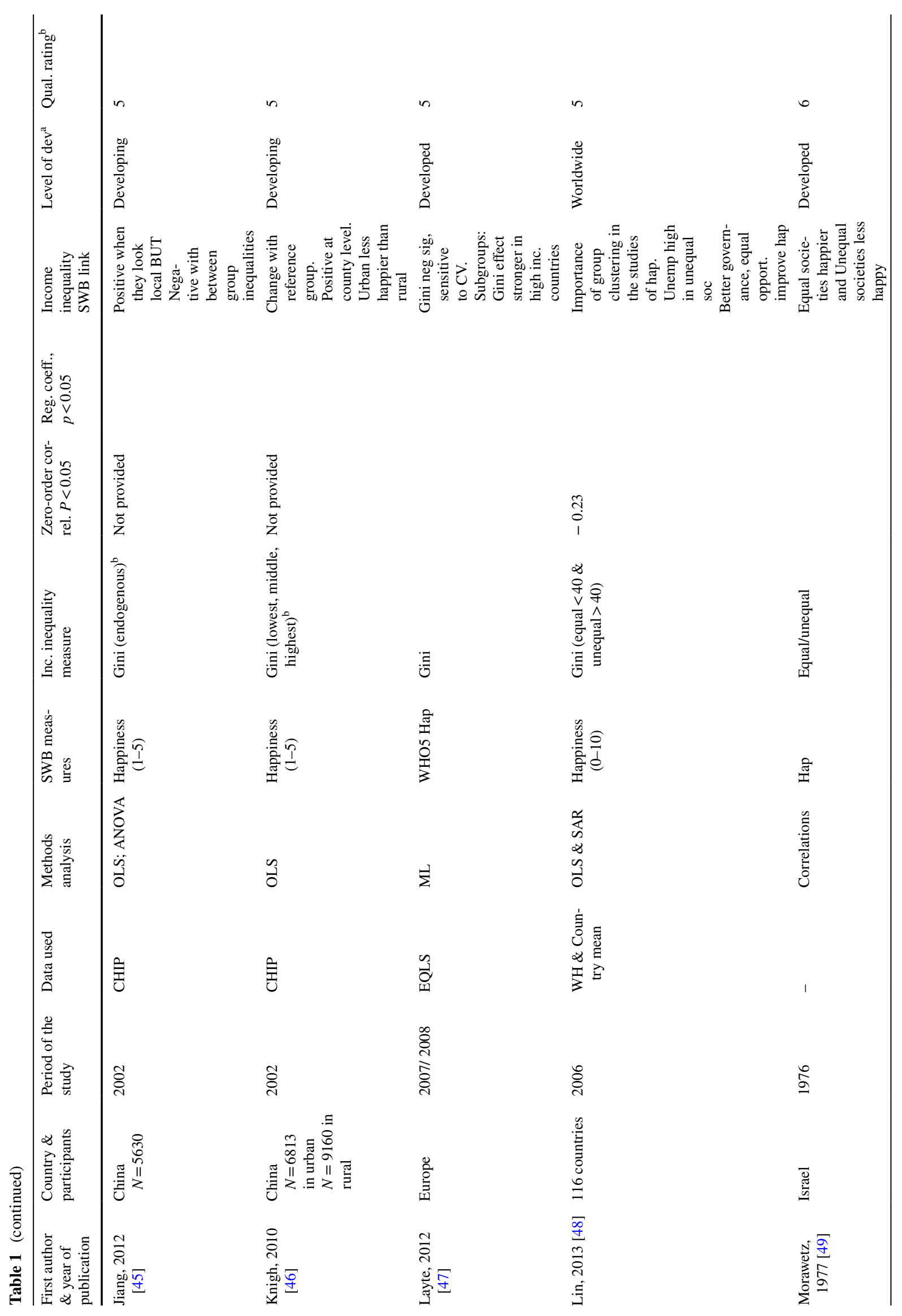




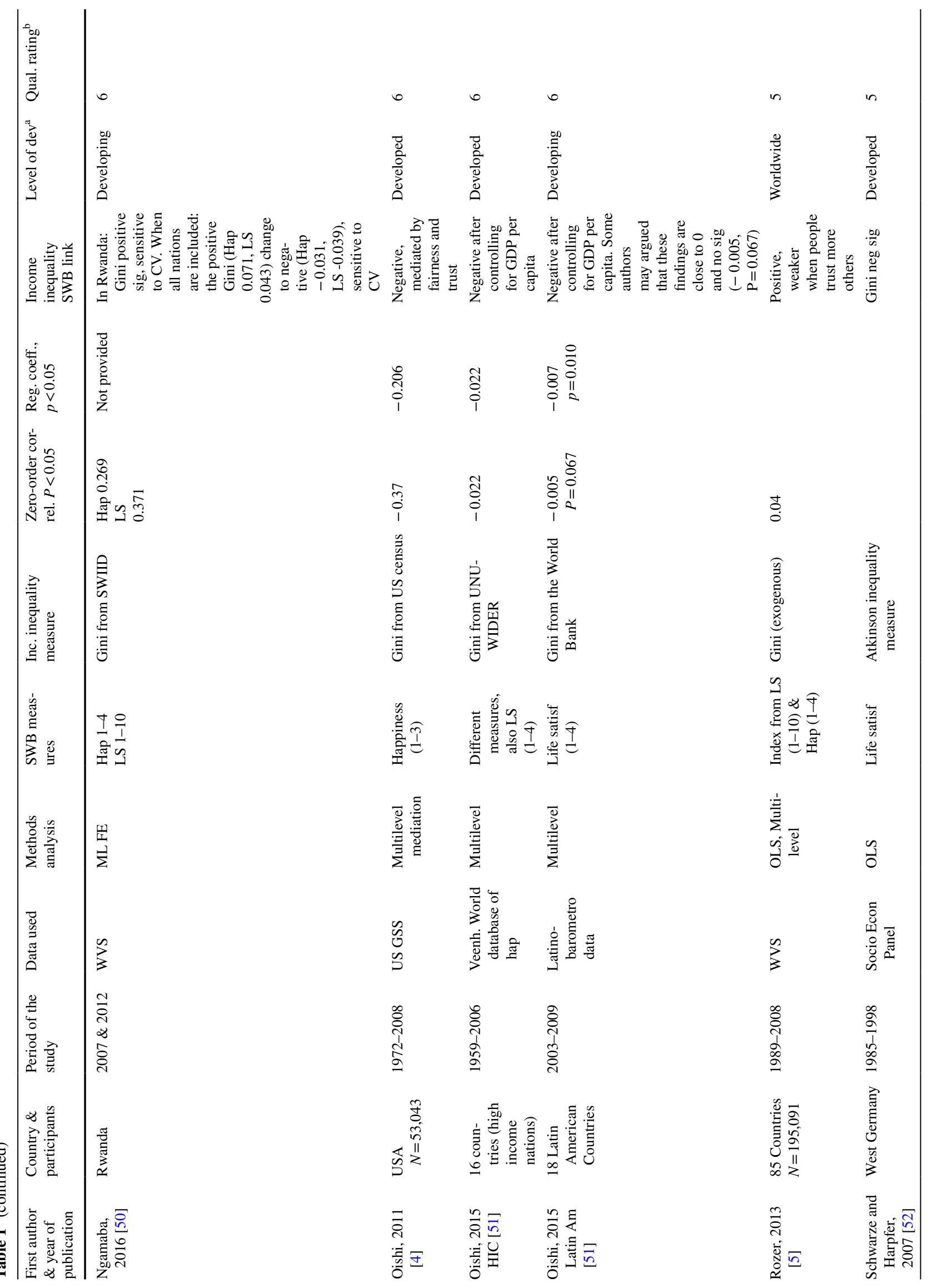




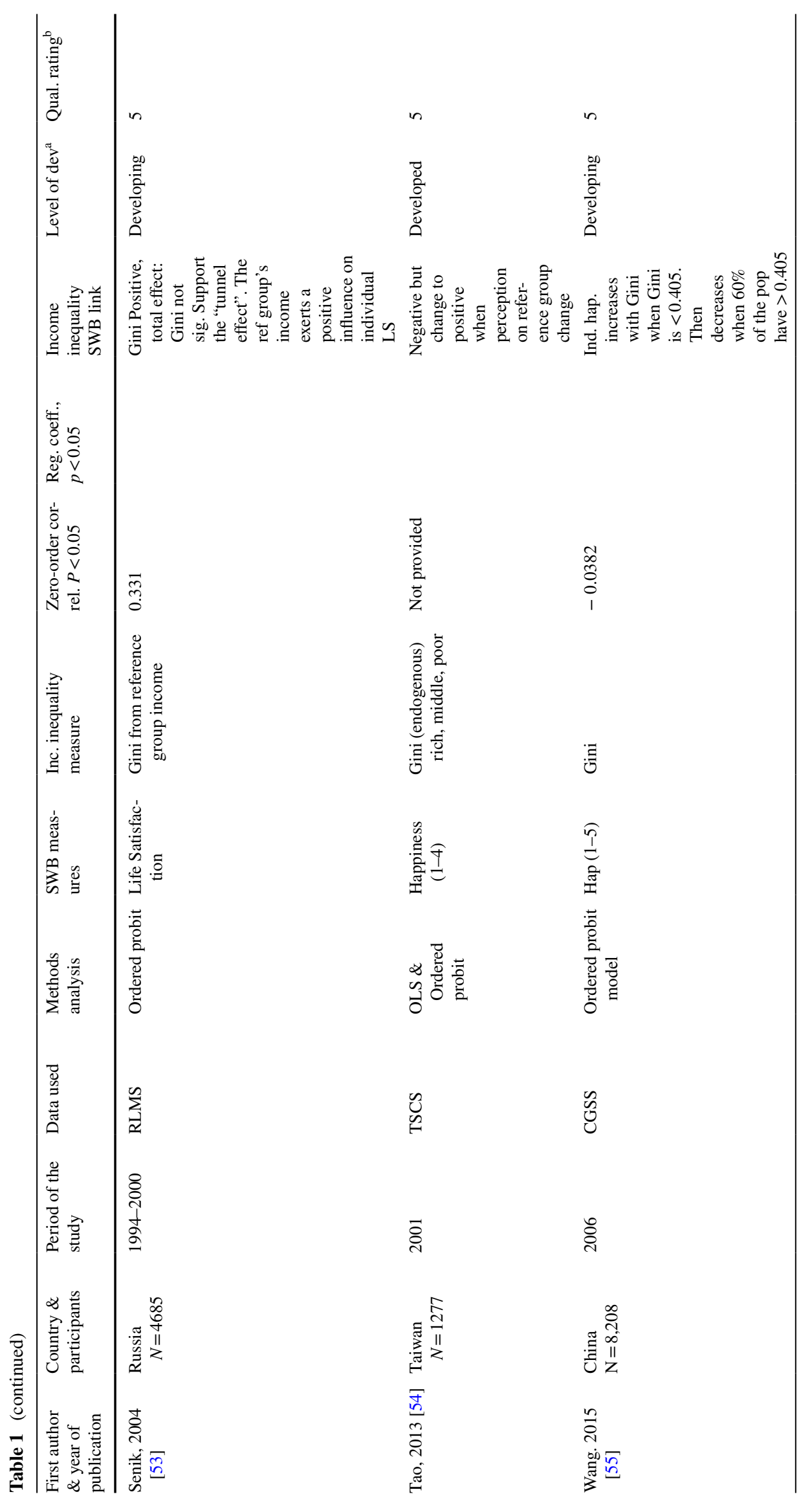




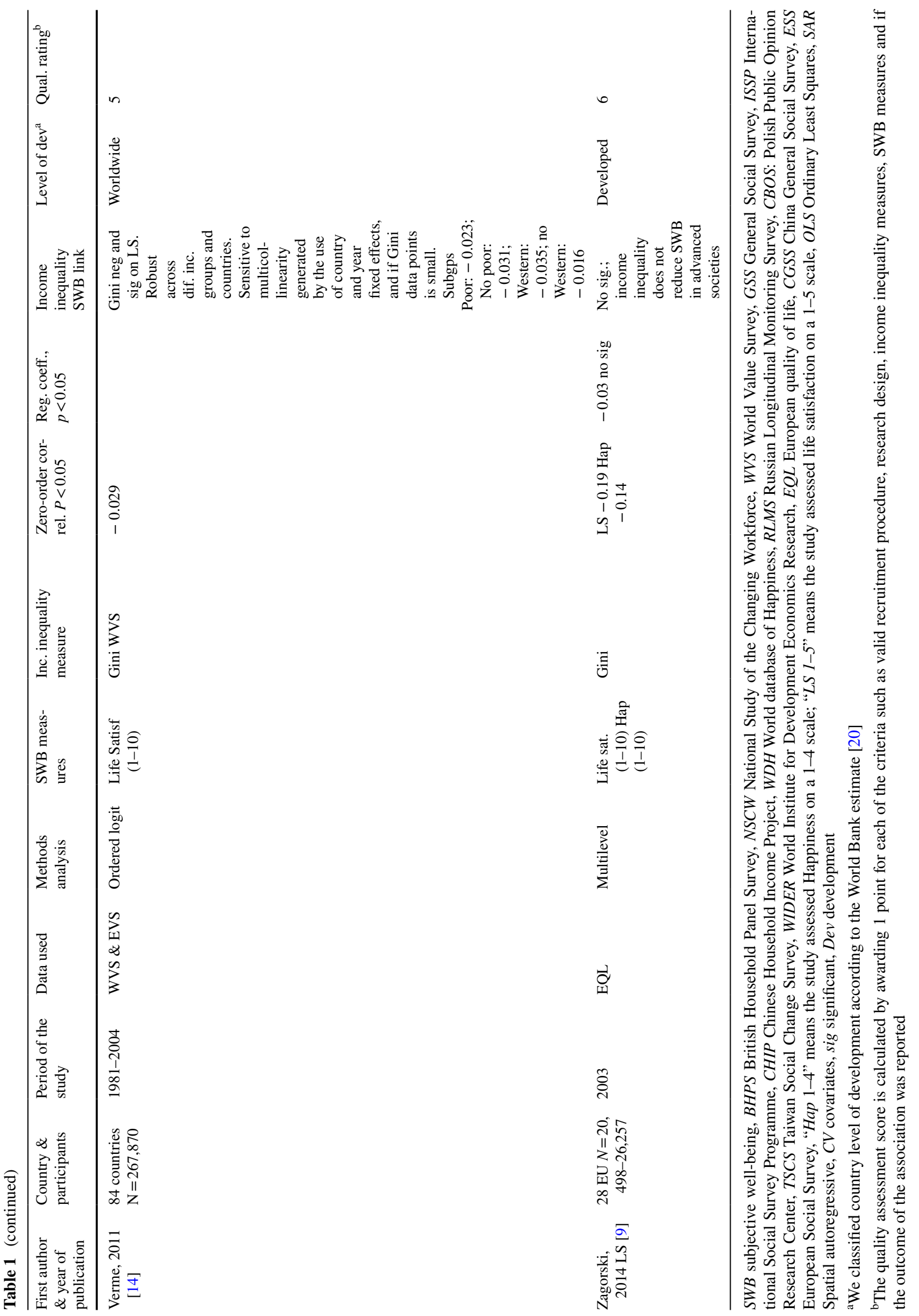


Fig. 1 PRISMA flow diagram (income inequality and SWB); source: $[15,27]$

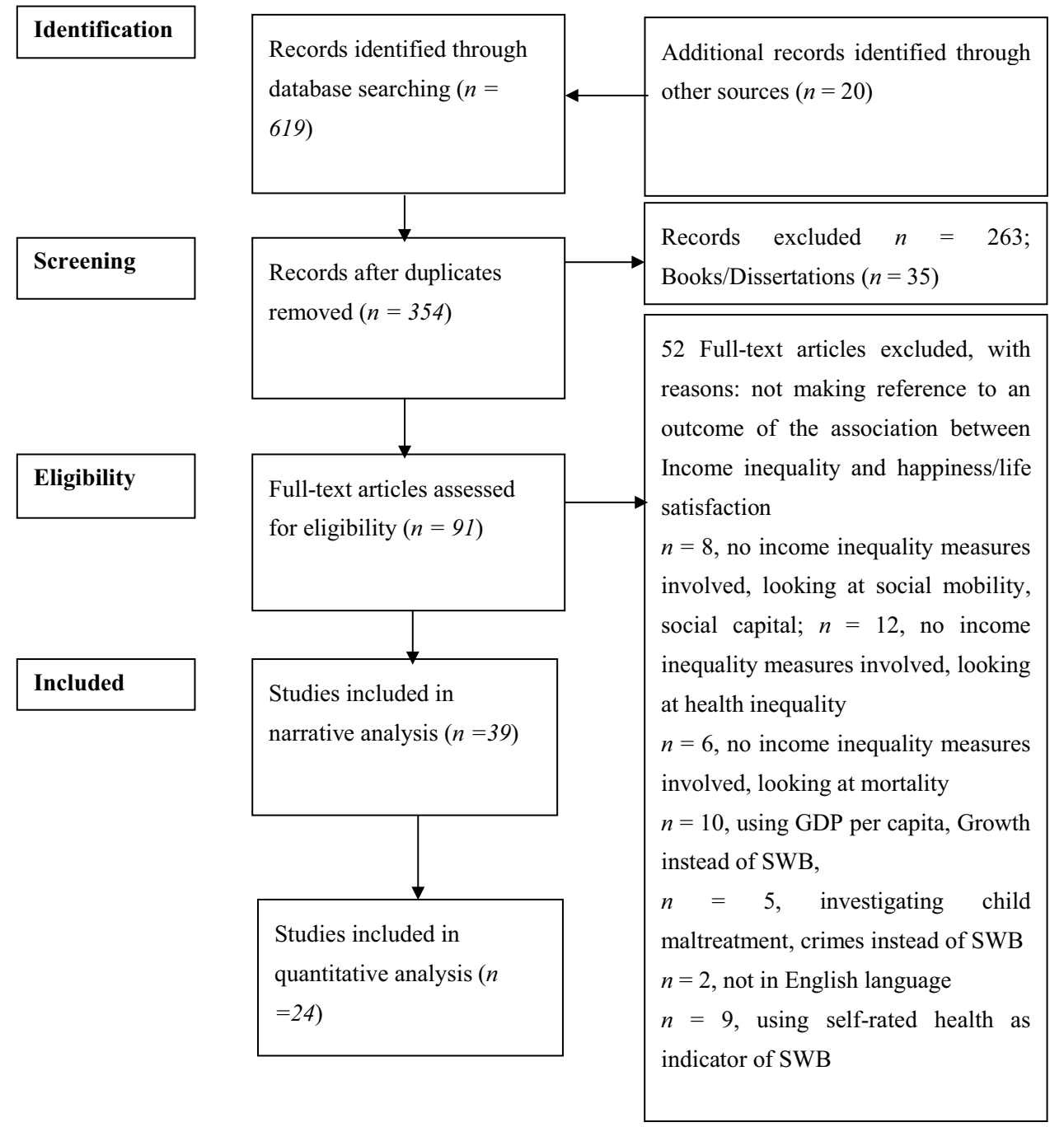

\section{SWB assessment (i.e. happiness versus life satisfaction)}

14/39 studies assessed happiness and 21 studies used life satisfaction to assess SWB. The remaining four studies used both happiness and life satisfaction to assess SWB. Of 14 studies using happiness to assess the SWB, eight reported a negative association and six reported a positive association with income inequality. Of 21 studies using life satisfaction to assess SWB, 12 reported a negative association, six reported a positive association and three found no relationship. The remaining four studies that used both happiness and life satisfaction reported negative $(n=2)$, positive $(n=1)$ and no $(n=1)$ associations.

\section{Country level of development}

Using the World Bank classification of countries [20], our narrative analysis shows that 21 studies were conducted in developed countries, of which 18 reported a statistically significant negative association between income inequality and
SWB and the remaining three report a statistically significant positive association. Studies that were conducted worldwide $(n=9)$ report both negative $(n=4)$ and positive $(n=4)$ associations, and one study found no association [44]. The remaining nine studies that were conducted in developing countries report a positive $(n=6)$ or no association $(n=3)$ between income inequality and SWB. Studies conducted in Russia, rural China and Rwanda report a positive association between income inequality and SWB [46, 50, 53, 56]. While all three countries are classified as developing countries, their GDP per capita varied considerably from $\$ 9092$ in Russia to $\$ 8027$ in China and \$697 in Rwanda [100].

\section{Geographic region}

Of 39 studies, one study (i.e. Alesina and colleagues) compared Europeans to Americans [8] and found that the association between income inequality and SWB was stronger among Europeans than Americans. A cross-national study investigating the association between income inequality 
and SWB in 119 nations reported mixed findings: a negative association in the Western world (i.e. Western European countries, US, Canada, Australia and New Zealand); a slightly positive association in Eastern Europe, Asia and Latin America (after controlling for wealth) and no association in Africa [6]. Berg and Veenhoven [6] reported only the overall association and did not report the quantitative data supporting the negative association in Western countries or either the positive or no association in other regions [6].

The way income inequality was operationalised (i.e. exogenous Gini and endogenous Gini)

The majority of studies $(n=26)$ used exogenous Gini (i.e. extracted from nation-level data) and the remaining 13 studies used endogenous Gini (i.e. calculated from individuals' responses). Studies that used endogenous Gini were longitudinal studies and conducted in single countries such as the UK, Russia, China and Poland, whereas studies using exogenous Gini $(n=18)$ were mainly cross-sectional. In both groups, the studies have reported both negative and positive associations between income inequality and SWB regardless of whether the Gini coefficient was exogenous or endogenous.

\section{Meta-analysis of the association between income inequality and SWB}

\section{Overall relationship between income inequality and $S W B$}

Figure 2 presents the forest plot of the main analysis, namely the overall relationship between income inequality and SWB across the 24 studies that provided the relevant statistics. The overall pooled effect size was practically zero and non-significant, suggesting that there is no association between income inequality and SWB (pooled $r=0.01,95 \%$ CI -0.08 to 0.06$)$ and the heterogeneity between studies was high $\left(Q=563.10, I^{2}=95.74 \%, p<0.001\right)$. As shown in Fig. 2, the effect sizes of the individual studies included in the meta-analysis differed considerably in direction and magnitude. Sixteen studies reported a negative association between income inequality and SWB, whereas eight studies reported a positive association between income inequality and SWB.

\section{Results of the subgroup analysis}

Country level of development Of 24 studies eligible for the meta-analysis, 14 studies were conducted in developed countries (e.g. USA) versus five studies conducted in developing countries (e.g. China). The pooled effect sizes across studies based on populations from developed and developing countries were statistically significant in both groups indicating that the relationship between income inequality and SWB does differ across developed and developing countries (developed countries: pooled $r=-0.06,95 \% \mathrm{CI}$ -0.10 to -0.02 ; developing countries: pooled $r=0.16,95 \%$ CI 0.09-0.23). The results of the Cohen's $Q$ test confirmed that the magnitude of the correlation was significantly negative among studies conducted in developed countries and significantly positive among studies conducted in developing countries: Cohen's $q=24.556, p<0.05$ (See Fig. 3 in Appendix 3 (Supplementary Material)).

Geographic region (USA vs. European countries) Of 24 studies eligible for the meta-analysis, three studies were conducted in the USA versus seven studies conducted in European countries. The pooled effect sizes in these two regions (i.e. studies conducted in the European countries and the USA) were statistically significant indicating a negative association between income inequality and SWB (European countries: pooled $r=0.05,95 \% \mathrm{CI}-0.09$ to -0.01 ; USA pooled $r=-0.08,95 \%$ CI -0.14 to -0.01 ) (See Fig. 4 in Appendix 3 Supplementary Material).

SWB measures The meta-analysis involved eight studies that used happiness to assess SWB versus 18 studies that used life satisfaction to assess SWB. The main effect was not influenced by type of SWB measures (life satisfaction: pooled $r=0.02,95 \% \mathrm{CI}-0.06$ to 0.10 ; happiness: pooled $r=-0.08,95 \%$ CI -0.18 to 0.03 ) (See Fig. 5 in Appendix 3 (Supplementary Material)).

Exogenous Gini versus endogenous Gini Of 24 studies eligible for the meta-analysis, the majority of studies $(n=18)$ used exogenous Gini, while the remaining six studies used endogenous Gini. The pooled effect sizes between studies that used exogenous Gini and studies that used endogenous Gini were statistically non-significant indicating that the relationship between income inequality and SWB does not vary when exogenous or endogenous Gini was used (exogenous Gini: pooled $r=-0.02,95 \% \mathrm{CI}$ -0.10 to 0.06 ; endogenous Gini: pooled $r=0.03,95 \% \mathrm{CI}$ -0.09 to 0.16) (See Fig. 6 in Appendix 3 (Supplementary Material).

\section{Discussion}

The association between income inequality and SWB is complex and highly dependent on methodological variations across studies. The findings of this review do not support a link between income inequality and SWB in general. Subgroup analyses revealed that the association between income inequality and SWB is significantly influenced by the country economic development. The association between income 
inequality and SWB is significantly negative in developed countries (pooled $r=-0.06,95 \% \mathrm{CI}-0.10$ to -0.02 ) but significantly positive in developing countries (pooled $r=0.16,95 \%$ CI $0.09-0.23$ ).

Nevertheless, the association between income inequality and SWB was not influenced by (a) the measure used to assess SWB (i.e. happiness and life satisfaction), (b) geographic region (i.e. studies conducted in the USA versus studies conducted in the European countries) or (c) the way income inequality was operationalised (i.e. exogenous Gini vs. endogenous Gini).

\section{How to interpret the exploratory findings?}

Our findings suggest that the direction of the association between income inequality and SWB differs between developed and developing countries. Differences in different preferences for income inequality might explain this finding. For example, the evolutionary modernisation theory $[11,58]$ hypothesises differences in tolerance for income inequality as economies move from developing to developed countries. According to this theory $[11,58]$, people in developing countries might perceive income inequality as an economic opportunity or incentive to work, innovate and develop new technologies and therefore as a more core determinant of their well-being compared to developed countries. In contrast, technology, economic growth and innovation might be taken for granted in developed countries, meaning that income inequality may be perceived as a treat rather than a challenge [11, 59]. Moreover, our findings do support the "tunnel" effect theory suggesting that the rise of income inequality may signal future mobility and an increase of SWB [60]. The "tunnel" effect theory supports the idea that people in developing countries may tolerate income inequality by observing other people's increasingly rapid progression and interpreting this evolution as a sign that their turn will come soon [60, 61]. A study conducted in Poland found that when an increase of income inequality was associated with growth and when it was perceived to change rapidly, people were more satisfied with their lives [39]. For example, Berg has suggested that "income inequality is not necessary harmful to well-being. Beja added that people may accept income inequality when they see the possibilities to rise above their current position" ([12], p. 153).

\section{Research and social policy implications}

The main contribution of this systematic review and metaanalysis is that the country level of development influences the link between income inequality and SWB: income inequality is more likely to be a contributor to SWB in citizens of developing countries than in developed countries. Reducing income inequality could be a potentially fruitful approach for governments and policy makers of developed countries as a means of improving the SWB of their citizens $[11,12]$. The inverse association of SWB with income inequality in developing countries suggests that income inequality is more likely to be seen as job opportunities for innovation in these countries. However, this review was only based on cross-sectional studies and no causal inferences are allowed; longitudinal studies are needed prior to forming any causal links. The association between income inequality and SWB was not influenced by the measure used to assess SWB, geographic region or the way income inequality was operationalised. Our findings are in line with previous research conducted in OECD countries suggesting no association between income inequality and SWB [9] "the best evidence that we have to date is that redistribution beyond the minimum for advanced societies does not enhance subjective well-being/quality of life" ([9], p. 1107). Nevertheless, further studies are needed to understand the circumstances in which income inequality reduces SWB [3, 4, 62] versus the circumstances in which income inequality is not necessarily harmful to SWB $[6,12]$. For example, extraordinary circumstances such as the great recession may affect how inequality is associated to subjective well-being. This gap in knowledge is critical because some government and policy makers still ask whether people care about income inequality and if income inequality affects SWB. At present, the evidence base is weak and cannot support strongly such decisions. Most importantly, the present systematic review highlights the need to produce a higher-quality evidence base to support social and political decisions relating to income inequality and SWB, both with respect to identifying (a) what are the consequences of income inequality and (b) what are the antecedents of SWB.

\section{Strengths and limitations}

This review has several strengths. First, the search was conducted according to PRISMA published guidance [27]. Consistent with the Cochrane guidance [16], the search strategy comprised a thorough literature review, screening of reference lists and contacting authors for additional information. Second, this is the first systematic review that investigated the association between income inequality and SWB, and therefore the findings of this review have the potential to inform the literature in this area.

Nevertheless, it is important to recognise few key limitations of this review. First, the preponderance of cross-sectional studies means that it was impossible to establish a temporal or causal relationship between income inequality and SWB. Second, the poor reporting of data in combination with the use of different analytic approaches precluded any firm conclusions about the direction and strength of the association between income inequality and SWB. Future 
Fig. 2 Forest plot displaying meta-analysis of the correlations between income inequality and SWB across 24 independent samples

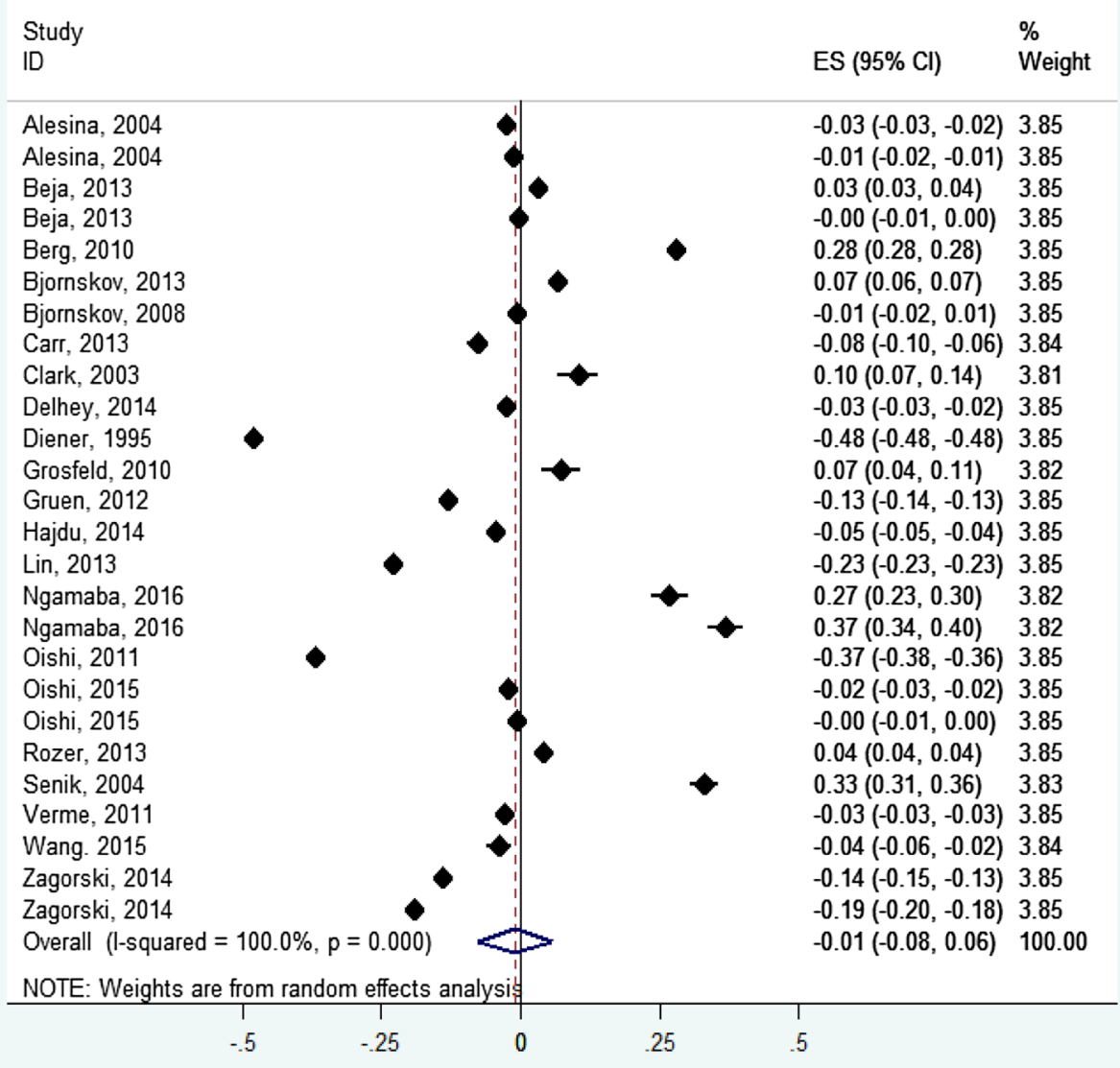

studies are encouraged to concentrate on establishing an initial correlation between income inequality and SWB before embarking on multivariate analyses. Third, this study investigated the relationship between income inequality and SWB. Nevertheless, previous studies investigating people's quality of life have reported a link between inequality, SWB and health status $[5,9]$. Further studies are needed to systematically investigate the association between income inequality, SWB and health status [1,2]. Finally, the majority of studies included in this review were conducted in developed countries $(N=14)$ and only five studies were conducted in developing countries. This is problematic in terms of the representativeness for the purpose of global decision-making. More studies are needed to be performed in developing countries. Due to limitations in the available data, we were unable to compare Latin America to Europe or the USA because only one Latin America country had data amenable to meta-analysis. Social and political history may affect the association between income inequality and SWB because Inglehart et al. report that, with the same level of wealth, Latin America is happier than their counterparts in Ex-Communist nations [59]. We strongly encourage more methodologically sound investigations to examine the association between income inequality and SWB and to elucidate current gaps and inconsistencies.

\section{Conclusion}

In conclusion, this is the first systematic synthesis of the literature regarding the link between income inequality and SWB. The main finding of this review is that the association between income inequality and SWB is complex. More rigorous investigations are needed to elucidate the link between income inequality and SWB, and to identify what are the antecedents and consequences of income inequality and SWB taking into account the country development level.

Acknowledgements We thank the authors who provided additional information allowing us to conduct this systematic review and metaanalysis. We would also like to thank the editor and external reviewers for their useful comments and suggestions. This research was supported by the NIHR Manchester Biomedical Research Centre.

\section{Compliance with ethical standards}

Conflict of interest The authors declare no conflicts of interest. 
Ethical approval No human participants were involved in the article as it is a review of previously published research.

Open Access This article is distributed under the terms of the Creative Commons Attribution 4.0 International License (http://creativecommons.org/licenses/by/4.0/), which permits unrestricted use, distribution, and reproduction in any medium, provided you give appropriate credit to the original author(s) and the source, provide a link to the Creative Commons license, and indicate if changes were made.

\section{References}

1. Dolan, P., Peasgood, T., \& White, M. (2008). Do we really know what makes us happy? A review of the economic literature on the factors associated with subjective well-being. Journal of Economic Psychology, 29(1), 94-122.

2. Fleche, S., Smith, C., \& Sorsa, P. (2011). Exploring determinants of subjective wellbeing in OECD countries: Evidence from the World Value Survey. Paris: OECD Economics Department.

3. Wilkinson, R., \& Pickett, K. (2010). The spirit level: Why equality better for everyone. London: Penguin.

4. Oishi, S., Kesebir, S., \& Diener, E. (2011). Income inequality and happiness. Psychological Science, 22(9), 1095-1100.

5. Rozer, J., \& Kraaykamp, G. (2013). Income inequality and subjective well-being: A cross-national study on the conditional effects of individual and national characteristics. Social Indicators Research, 113(3), 1009-1023.

6. Berg, M., \& Veenhoven, R. (2010). Income inequality and happiness in 119 nations: in search for an optimum that does not appear to exist. In B. Greve, (Ed.), Happiness and social policy in Europe (pp. 174-194). Cheltenham: Edward Elgar.

7. Wilkinson, R., \& Pickett, K. (2009). The spirit level: Why more equal societies almost always do better. London: Allen Lane Penguin.

8. Alesina, A., Di Tella, R., \& MacCulloch, R. (2004). Inequality and happiness: are Europeans and Americans different? Journal of Public Economics, 88(9-10), 2009-2042.

9. Zagorski, K., et al. (2014). Does national income inequality affect individuals' quality of life in Europe? Inequality, happiness, finances, and health. Social Indicators Research, 117(3), 1089-1110.

10. Kahneman, D., \& Deaton, A., (2010) High income improves evaluation of life but not emotional well-being. Proceedings of the National Academy of Sciences of the United States of America, 107(38), 16489-16493.

11. Inglehart, R. (1997). Modernization and post modernization: Cultural, economic, and political change in 43 societies. Princeton: Princeton University Press.

12. Beja, E. L. (2014). Subjective well-being analysis of income inequality: Evidence for the industrialized and emerging economies. Applied Research in Quality of Life, 9(2), 139-156.

13. Kalmijn, W., \& Veenhoven, R. (2005). Measuring inequality of happiness in nations: In search for proper statistics. Journal of Happiness Studies, 6(4), 357-396.

14. Verme, P., (2011). Life satisfaction and income inequality. Review of Income and Wealth, 57(1), 111-137.

15. Clark, A., et al. (2005). Heterogeneity in reported well-being: Evidence from twelve European countries. Economic Journal, 115(502), C118-C132.

16. Higgins, J. P. T., \& Green, S. (2011). Cochrane Handbook for Systematic Reviews of Interventions. London: The Cochrane Collaboration.
17. Smith, R. L., Ager, J. W., \& Williams, D. L. (1992). Suppressor variables in multiple-regression correlation. Educational and Psychological Measurement, 52(1), 17-29.

18. Clark, A. E., \& Oswald, A. J., (2006). The curved relationship between subjective well-being and age. PSE Working Papers No 2006-29.

19. Vanhoutte, B. (2012). Measuring subjective well-being in later life: a review, in CCSR Paper 2012-06. Manchester: Centre for Census and Survey Research

20. World_Bank.(2016). World Bank new country classifications. Washington, DC: The World Bank Group.

21. Nielsen, L., (2011). Classifications of countries based on their level of development: how it is done and how it could be done. In IMF Working Paper: Strategy, Policy, and Review Department. Washington, DC: IMF.

22. Stata (2013). Stata 13.1 statistics/data analysis. Texas: Stata Press.

23. Cohen, J., \& Power Primer, A. (1992). A power primer. Psychological Bulletin, 112(1), 155-159.

24. Cohen, J. (1969). Statistical power analysis for the behavioral sciences. London: Academic Press.

25. Cohen, J., \& Cohen, P. (1983). Applied multiple regression/ correlation analysis for the behavioral sciences. Hillsdale, $\mathrm{NJ}$ : Erlbaum.

26. Preacher, K. J. (2002). Calculation for the test of the difference between two independent correlation coefficients [Computer software]. Quantpsy: Vanderbilt University.

27. Moher, D., et al. (2009). Preferred reporting items for systematic reviews and meta-analyses: The prisma statement. PLOS Medicine, 6(7), e1000097.

28. Bjornskov, C., et al. (2013). Inequality and happiness: When perceived social mobility and economic reality do not match. Journal of Economic Behavior \& Organization, 91, 75-92.

29. Hagerty, M. R. (2000). Social comparisons of income in one's community: Evidence from national surveys of income and happiness. Journal of Personality and Social Psychology, 78(4), 764-771.

30. Blanchflower, D. G., \& Oswald, A. J. (2004). Well-being over time in Britain and the USA. Journal of Public Economics, 88(7-8), 1359-1386.

31. Bjornskov, C., Dreher, A., \& Fischer, J. (2008). On the relation between income inequality and happiness do fairness perceptions matter? In Cesifo Conference on Ethics and Economics,. Munich: CESIFO group. Retrieved October 18, 2017, from http://www. cesifo-group.de.

32. Carr, M. D. (2013). Local area inequality and worker well-being. Review of Social Economy, 71(1), 44-64.

33. Clark, A., (2003). Inequality-aversion and income mobility: A direct test. DELTA Working Papers Series. Paris: RePEc.

34. Delhey, J., \& Dragolov, G. (2014). Why inequality makes Europeans less happy: The role of distrust, status anxiety, and perceived conflict. European Sociological Review, 30(2), 151-165.

35. Diener, E., Diener, M., \& Diener, C. (1995). Factors predicting the subjective well-being of nations. Journal of Personality and Social Psychology, 69(5), 851-864.

36. Dynan, K. E., \& Ravina, E. (2007). Increasing income inequality, external habits, and self-reported happiness. American Economic Review, 97(2), 226-231.

37. Fahey, T., \& Smyth, E. (2004). In W. A. Arts \& L. Halman (Eds.), The link between subjective well-being and objective conditions in European societies, in European values at the turn of the millennium. Leiden: Brill.

38. Graham, C., \& Felton, A. (2006). Inequality and happiness: Insights from Latin America. Journal of Economic Inequality, 4, 107-122. 
39. Grosfeld, I., \& Senik, C. (2010). The emerging aversion to inequality. Economics of Transition, 18(1), 1-26.

40. Gruen, C., \& Klasen, S. (2012). Has transition improved wellbeing? Economic Systems, 36(1), 11-30.

41. Hajdu, T., \& Hajdu, G. (2014). Reduction of income inequality and subjective well-being in Europe. Economics-the Open Access Open-Assessment E-Journal, 8, 201435.

42. Haller, M., \& Hadler, M. (2006). How social relations and structures can produce happiness and unhappiness: An international comparative analysis. Social Indicators Research, 75(2), 169-216.

43. Helliwell, J. F. (2003). How's life? Combining individual and national variables to explain subjective well-being. Economic Modelling, 20(2), 331-360.

44. Helliwell, J., \& Huang, H. (2008). How's your government? International evidence linking good government and well-being. British Journal of Political Science, 38, 595-619.

45. Jiang, S., Lu, M., \& Sato, H. (2012). Identity, inequality, and happiness: Evidence from urban China. World Development, 40(6), 1190-1200.

46. Knight, J., \& Gunatilaka, R. (2010). The rural-urban divide in China: income but not happiness? Journal of Development Studies, 46(3), 506-534.

47. Layte, R. (2012). The association between income inequality and mental health: Testing status anxiety, social capital, and neomaterialist explanations. European Sociological Review, 28(4), 498-511.

48. Lin, C. -H. A., Lahiri, S., \& Hsu, C. -P. (2014). Happiness and regional segmentation: Does space matter? Journal of Happiness Studies, 15(1), 57-83.

49. Morawetz, D., et al. (1977). Income distribution and self-rated happiness: some empirical evidence. The Economic Journal, 87(347), 511-522.

50. Ngamaba, H. K. (2016). Happiness and life satisfaction in Rwanda. Journal of Psychology in Africa, 26(5), 407-414.

51. Oishi, S., \& Kesebir, S. (2015). Income inequality explains why economic growth does not always translate to an increase in happiness. Psychological Science, 26(10), 1630-1638.
52. Schwarze, J., \& Harpfer, M. (2007). Are people inequality averse, and do they prefer redistribution by the state? Evidence from German longitudinal data on life satisfaction. Journal of Socio-Economics, 36, 233-249.

53. Senik, C. (2004). When information dominates comparisonLearning from Russian subjective panel data. Journal of Public Economics, 88(9-10), 2099-2123.

54. Tao, H. -L., \& Chiu, S. -Y. (2013). Income growth, redistribution, and subjective well-being in Taiwan-a simulation study. Applied Economics, 45(6), 775-791.

55. Wang, P., Pan, J., \& Luo, Z. (2015). The impact of income inequality on individual happiness: Evidence from China. Social Indicators Research, 121(2), 413-435.

56. Wang, X., et al. (2015). Linking health states to subjective wellbeing: An empirical study of 5854 rural residents in China. Public health, 129(6), 655-666.

57. World Bank estimate. (2015). Retrieved October 18, 2017, from https://data.worldbank.org/indicator/NY.GDP.PCAP.CD.

58. Inaba, Y. (2009). Social capital and health in Japan: What has been confirmed and what has not. A commentary on Ichida and on Fujisawa. Social Science \& Medicine, 69(4), 506-508.

59. Inglehart, R., et al. (2008). Development, freedom, and rising happiness: A global perspective (1981-2007). Perspectives on Psychological Science, 3(4), 264-285.

60. Hirschman, A. O., \& Rothschild, M. (1973). The changing tolerance for income inequality in the course of economic development. The Quarterly Journal of Economics, 87(4), 544-566.

61. Tomes, N. (1986). Income distribution, happiness and satisfaction: A direct test of the interdependent preferences model. Journal of Economic Psychology, 7(4), 425-446.

62. Bjornstrom, E. E. (2011). An examination of the relationship between neighborhood income inequality, social resources, and obesity in Los Angeles County. American Journal of Health Promotion, 26(2), 109-115. 